\title{
Questionnaire Survey on Current Red Blood Cell Transport and Storage in Korea for Reducing Wastage
}

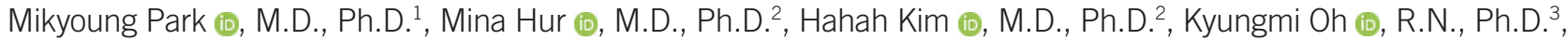

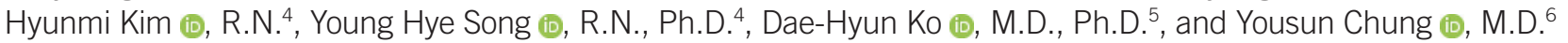 \\ ${ }^{1}$ Department of Laboratory Medicine, Eunpyeong St. Mary's Hospital, College of Medicine, The Catholic University of Korea, Seoul, Korea; ${ }^{2}$ Department of \\ Laboratory Medicine, Konkuk University School of Medicine, Seoul, Korea; ${ }^{3}$ Department of Nursing, Kyungbok University, Namyangju, Korea; ${ }^{4}$ Department \\ of Nursing, Konkuk University Medical Center, Seoul, Korea; ${ }^{5}$ Department of Laboratory Medicine, University of Ulsan College of Medicine and Asan Medical \\ Center, Seoul, Korea; ${ }^{6}$ Department of Laboratory Medicine, Hallym University College of Medicine, Seoul, Korea
}

Background: To ensure safe red blood cell (RBC) transfusion practice, it is important to comply with storage and transport requirements of RBC units. We conducted a comprehensive survey on the practice of RBC transport and storage to explore the awareness of and compliance with the 30-minute rule, the current status of RBC unit transport, and possible utility of temperature indicators (TIs) to reduce RBC wastage.

Methods: From June to August of 2019, 64 blood bank physicians (14 questions) in 64 secondary- and tertiary-care hospitals and 673 nurses (13 questions) in 42 tertiary-care hospitals replied to a questionnaire survey. The results of the survey were analyzed with descriptive statistics.

Results: Among the physicians surveyed, $97.0 \%(\mathrm{~N}=62)$ of hospitals had transfusion guidelines in place. The RBC wastage in 2018 ranged from less than five units to more than 200 units. Among the nurses surveyed, 99.4\% ( $N=669)$ were aware of and complied with the 30-minute rule; $13.5 \%(\mathrm{~N}=91)$ of the nurses had experience of RBC wastage due to violation of the 30 -minute rule. Both physicians $(67 \%, N=43)$ and nurses $(83.1 \%, N=559)$ responded that TIs would help reduce RBC wastage.

Conclusions: This is the first survey on the practices related to RBC transport and storage in Korea. This study provides fundamental data on current practice for the blood cold chain, insights into RBC wastage, and highlights the utility of TIs.

Key Words: Red blood cells, Survey, Transport, Storage, 30-minute rule, Temperaturesensitive indicator, Wastage
Received: August 10, 2021

Revision received: October 13, 2021

Accepted: November 8, 2021

\section{Corresponding author:}

Mina Hur, M.D., Ph.D.

Department of Laboratory Medicine,

Konkuk University School of Medicine, Konkuk University Medical Center, 120-1

Neungdong-ro, Hwayang-dong, Gwangjingu, Seoul 05030, Korea

Tel: +82-2-2030-5581

E-mail: dearmina@hanmail.net

\section{INTRODUCTION}

Red blood cell (RBC) units are the most widely transfused component during patient care, including critically and non-critically ill patients $[1,2]$. For safe RBC transfusion practice, it is important to comply with storage and transport requirements of RBC units [3-5]. RBC units should be kept at $1-6^{\circ} \mathrm{C}$ during storage in a blood bank refrigerator and at $1-10^{\circ} \mathrm{C}$ during transport, according to the American Association of Blood Banks [3]. The
Korean transfusion guidelines state that RBC units exceeding a core temperature (CT) of $10^{\circ} \mathrm{C}$ should not be retrieved from the blood bank [4].

Based on a study performed in the early 1970s, the 30-minute rule has been used as a customary time limit; to ensure that the CT of RBC units does not exceed $10^{\circ} \mathrm{C}$, in clinical practice, RBC transfusion should be initiated within 30 minutes after issue from the blood bank [4, 6-8]. The World Health Organization (WHO) states that RBC units kept out of the blood bank re- 
frigerator for over 30 minutes should be discarded; if RBC units are not transfused immediately at wards or operating rooms (ORs) without blood refrigerators, RBC units should be issued from the blood bank just prior to transfusion [7]. To ensure that the temperature of $\mathrm{RBC}$ units remains below $10^{\circ} \mathrm{C}$ during transport, each transport container needs to be in a controlled temperature condition [8].

An international survey showed that the overall wastage rate of issued RBC units ranged from $1.9 \%$ to $2.8 \%$ in the United States, Africa, Europe, and Australia; up to $1.4 \%$ of RBC units were discarded due to an improper transport container or violation of the transport temperature requirement [9]. The 30-minute rule was also suggested to cause increased RBC wastage $[10,11]$. RBC wastage due to violation of the 30 -minute rule or uncontrolled temperature ranged from $0.4 \%$ to $22.3 \%$ among all discarded RBC units [12, 13].

Temperature-sensitive indicators (TIS), which are adhesive labels with an irreversible color change at $10^{\circ} \mathrm{C}$, were recently introduced to transfusion practice to monitor the surface temperature (ST) of RBC units and are expected to help maintain the blood cold chain and reduce RBC wastage [5, 14-18]. However, some practical issues surrounding the use of current TIs remain with regard to heterogeneity and lack of standardization, questioning whether TIs are indeed useful for reducing RBC wastage in transfusion practice $[5,17]$.

The blood cold chain is a process to store and transport blood safely from the site of donation to the site of transfusion [8]. Nurses take a frontline role in RBC transfusion practice at bedside [7, 19, 20]. Therefore, both blood bank physicians and nurses must be aware of and comply with storage and transport requirements of RBC units to guarantee adequate transfusion practice and reduce RBC wastage [20-22]. To the best of our knowledge, there has been no published survey on RBC transport and storage practice including blood bank physicians as well as nurses in a real hospital setting. We conducted a comprehensive survey on the RBC cold chain practice to explore the awareness of and compliance with the 30-minute rule, the current status of RBC unit transport, and possible utility of TIs to reduce RBC wastage.

\section{MATERIALS AND METHODS}

\section{Study population}

This study was conducted as part of the 2019 Policy Research Service Project of the Korea Centers for Disease Control and Prevention, titled "The Efficient Management of Blood Resources using Temperature Indicators" (Number 2019E830400). The study protocol was approved by the Institutional Review Board of Konkuk University Medical Center (KUMC 2019-05-028). In June 2019, the survey and questionnaire were designed and critically reviewed by nine experts from three professional academic societies: Korean Society for Laboratory Medicine (KSLM), Korean Society of Blood Transfusion (KSBT), and Korean Nurses Association (KNA). The survey to blood bank physicians comprised a short questionnaire (with 13 questions) to assess the blood cold chain practice of RBC units in the blood bank. The survey was sent by e-mail or post to blood bank physicians who are certified members of KSLM or those of KSBT working at 93 secondary- or tertiary-care hospitals. A total of 64 blood bank physicians working at 64 hospitals (one physician per hospital) replied to the survey completely anonymously. Nurses working at 42 tertiary-care hospitals were sent a short questionnaire (with 15 questions) to assess nursing practice for the blood cold chain of RBC units; a total of 673 nurses replied to the survey completely anonymously. The surveys were conducted from June to August 2019, and the data were compiled in August 2019.

\section{Questionnaire surveys}

The questionnaire surveys consisted of basic demographic questions. For physicians, three questions on basic demographics were included: hospital size, geographic region in Korea, and status of certified members of KSLM. The 13 questions on blood bank practice were related to the existence and content of RBC transfusion guidelines at the hospital, criteria for discarding RBC units after issue or within the blood bank in the RBC transfusion guidelines, transport container to the ward after issue, ST monitoring of RBC units at transport after issue, total number of blood refrigerators at the ward or outpatient clinic, existence of a ward with a blood refrigerator, crossmatching tests in 2018, RBC units issued in 2018, RBC wastage in 2018, crossmatch to transfusion (C:T) ratio in 2018, expected utility of TIs to reduce RBC wastage, and reasons for the expected low utility of TIs to reduce RBC wastage. A blood refrigerator was defined as a refrigerator intended for only blood storage with an automated temperature monitoring system and an alarm when the temperature exceeds unacceptable levels [8]. RBC wastage was defined as discarded amounts of issued RBC units or those stored in the blood bank [9, 12].

For nurses, four questions on basic demographics were included: hospital size, geographic region in Korea, nursing department, and clinical experience as a nurse. The 15 questions on blood bank practice were related to the existence and content of nursing practice guidelines for RBC transfusion, criteria 
for discarding RBC units after issue in the nursing practice guidelines for RBC transfusion, use of a transport container to the ward after issue, types of transport containers to the ward after issue, ST monitoring of RBC units during transport after issue, blood refrigerator located at the ward or outpatient clinic, storage time limit of RBC units in the blood refrigerator at the ward, monitoring of temperature of the blood refrigerator at the ward, knowledge of the 30-minute rule, compliance with the 30-minute rule, experience of RBC unit discarding due to violation of the 30-minute rule, reasons for $\mathrm{RBC}$ unit discard due to violation of the 30minute rule, expected utility of Tls to reduce RBC wastage, and reasons for the expected low utility of TIs to reduce RBC wastage.

\section{Statistical analysis}

Data are presented as number (percentage). Descriptive statistics were used to summarize survey data. Statistical analysis was performed using the MedCalc software version 19.7.4 (MedCalc Software Bvba, Ostend, Belgium) and Microsoft Excel 2019 (Microsoft Corporation, Redmond, WA, USA).

\section{RESULTS}

Basic demographics of the total respondents are summarized in Table 1 . The majority of respondents were from hospitals with 500-999 beds, accounting for 54.7\% ( $\mathrm{N}=35)$ of blood bank physicians and $67.5 \%(\mathrm{~N}=454)$ of nurses. Most of the respondents' affiliated hospitals were located in a metropolitan area (Seoul, Inchon, and Gyeonggi-do). The majority of physicians were certified blood bank physicians $(96.9 \%, N=62)$. Most of the nurses' affiliated departments of nursing were the general ward (GW) and intensive care unit (ICU), and $47.5 \%(\mathrm{~N}=320)$ of the nurses had more than 10 years of nursing experience.

The survey results of blood bank physicians are summarized in Table 2. The majority (96.9\%) indicated the existence of transfusion guidelines at their hospitals, including the 30-minute rule; 85.9\% $(N=55)$ of physicians stated that blood refrigerators are equipped at hospital wards. The number of RBC units issued in 2018 ranged from $<500$ units to $>50,000$ units. Regarding the C:T ratio, $44.4 \%(\mathrm{~N}=28)$ and $14.3 \%(\mathrm{~N}=9)$ were below 1.1 and above 1.4 , respectively. Regarding the expected utility of TIs to reduce RBC wastage, $67 \%(N=43)$ and $33 \%(N=21)$ of blood bank physicians stated that TIs would have high and low utility, respectively. Reasons for the expected low utility of TIs were as follows: low RBC wastage due to violation of the 30-minute rule $(81.0 \%, \mathrm{~N}=17)$, possibility of increasing RBC wastage
Table 1. Basic demographics of the survey respondents $(N=737)$

\begin{tabular}{|c|c|c|}
\hline \multirow[b]{2}{*}{ Variables } & \multicolumn{2}{|c|}{$\mathrm{N}$ of respondents (\%) } \\
\hline & $\begin{array}{c}\text { Blood bank } \\
\text { physicians } \\
(\mathrm{N}=64)\end{array}$ & $\begin{array}{c}\text { Nurses } \\
(\mathrm{N}=673)\end{array}$ \\
\hline \multicolumn{3}{|l|}{ Hospital size } \\
\hline$<100$ beds & $0(0.0)$ & $1(0.1)$ \\
\hline 100-499 beds & $18(28.1)$ & $9(1.3)$ \\
\hline 500-999 beds & $35(54.7)$ & $454(67.5)$ \\
\hline $1,000-1,999$ beds & $8(12.5)$ & $126(18.7)$ \\
\hline 2,000-2,999 beds & $2(3.1)$ & $16(2.4)$ \\
\hline$\geq 3,000$ beds & $1(1.6)$ & $67(10.0)$ \\
\hline \multicolumn{3}{|l|}{ Geographic region in Korea } \\
\hline Seoul & $22(34.4)$ & $304(45.2)$ \\
\hline Incheon, Gyeonggi-do & $14(21.9)$ & 183 (27.2) \\
\hline Busan, Daegu, Gryengsang region & $9(14.1)$ & $67(10.0)$ \\
\hline Sejong, Daejeon, Chungcheong region & $8(12.5)$ & $34(5.1)$ \\
\hline Gwangju, Jeolla region & $6(9.4)$ & $82(12.2)$ \\
\hline Gangwon-do, Jeju-do & $5(7.8)$ & $3(0.4)$ \\
\hline Certified members of KSLM & $62(96.9)$ & N/A \\
\hline \multicolumn{3}{|l|}{ Nursing department } \\
\hline GW & $N / A$ & $439(65.2)$ \\
\hline ICU & & 114 (16.9) \\
\hline $\mathrm{OR}$ & & $37(5.5)$ \\
\hline ED & & $28(4.2)$ \\
\hline $\mathrm{OC}$ & & $26(3.9)$ \\
\hline Others & & $29(4.3)$ \\
\hline \multicolumn{3}{|l|}{ Clinical experience of as a nurse } \\
\hline$<1 \mathrm{yr}$ & $N / A$ & $57(8.5)$ \\
\hline $1-2.9 \mathrm{yr}$ & & $92(13.7)$ \\
\hline $3-4.9 \mathrm{yr}$ & & 89 (13.2) \\
\hline $5-9.9 \mathrm{yr}$ & & $115(17.1)$ \\
\hline$\geq 10 \mathrm{yr}$ & & $320(47.5)$ \\
\hline
\end{tabular}

Abbreviations: KSLM, Korean Society of Laboratory Medicine; GW, general ward; ICU, intensive care unit; OR, operating room; ED, emergency department; OC, outpatient clinic; N/A, not available; yr, year.

due to the fast color change of TIs $(52.4 \%, N=11)$, intra- or inter-observer variability in reading the color change of TIs (33.3\%, $\mathrm{N}=7$ ).

The survey results of nurses are summarized in Table 3. The majority of nurses indicated that their hospitals had existing nursing practice guidelines for RBC transfusion, which included the 30-minute rule as a standard for RBC unit discard, and they were aware of and complied with the 30-minute rule. Some nurses 
Park M, et al.

Survey on RBC Transport and Storage in Korea

Table 2. Summary of the survey to blood bank physicians $(N=64)$

\begin{tabular}{|c|c|}
\hline Questionnaire & $\mathrm{N}$ of respondents (\%) \\
\hline \multicolumn{2}{|l|}{ Presence of RBC transfusion guidelines } \\
\hline Yes & $63(98.4)$ \\
\hline No & $1(1.6)$ \\
\hline \multicolumn{2}{|l|}{ Contents of RBC transfusion guidelines* } \\
\hline Shipping and receiving $\mathrm{RBC}$ units from the blood center & $51(79.7)$ \\
\hline Storage temperature of RBC unit in the blood bank & $62(96.9)$ \\
\hline Transport of RBC units to the ward after issue & $56(87.5)$ \\
\hline RBC transfusion & $51(81.3)$ \\
\hline Standards for discard of RBC unit after issue* & $63(98.4)$ \\
\hline Criteria for discard of RBC units after issue or within the blood bank in RBC transfusion guidelines* & $63(98.4)$ \\
\hline Exposure to RT for over 30 minutes & $62(96.9)$ \\
\hline ST of RBC units to reach $10^{\circ} \mathrm{C}$ & $34(53.1)$ \\
\hline Damaged RBC units & $56(87.5)$ \\
\hline Contaminated RBC units & $53(82.8)$ \\
\hline Withdrawal of RBC transfusion due to the change of patient's condition & $39(60.9)$ \\
\hline Transfusion-related adverse reactions & $48(75.0)$ \\
\hline \multicolumn{2}{|l|}{ Transport container to ward after issue } \\
\hline Cooler only & $22(34.4)$ \\
\hline Cooler with refrigerant & $31(48.4)$ \\
\hline Cooler with refrigerant and $\mathrm{TI}$ & $1(1.6)$ \\
\hline Others (e.g., cool bag, plastic box, plastic bag) & $10(15.6)$ \\
\hline ST monitoring of RBC units at transport after issue & $1(1.6)$ \\
\hline Total numbers of blood refrigerators at ward or outpatient clinic & $55(85.9)$ \\
\hline 1 & $26(47.3)$ \\
\hline 2 & $12(21.8)$ \\
\hline 3 & $3(5.5)$ \\
\hline$\geq 4$ & $14(25.4)$ \\
\hline Ward with blood refrigerator* & $55(85.9)$ \\
\hline GW & $3(5.5)$ \\
\hline ICU & $21(38.2)$ \\
\hline $\mathrm{OR}$ & $52(94.5)$ \\
\hline ED & $20(36.4)$ \\
\hline OC & $1(1.8)$ \\
\hline \multicolumn{2}{|l|}{ Crossmatching tests in $2018^{\dagger}$} \\
\hline$<1,000$ & 2 (3.2) \\
\hline $1,000-4,999$ & $10(15.9)$ \\
\hline $5,000-9,999$ & $13(20.6)$ \\
\hline $10,000-49,999$ & $32(50.8)$ \\
\hline $50,000-99,999$ & $5(7.9)$ \\
\hline$\geq 100,000$ & $1(1.6)$ \\
\hline
\end{tabular}


Table 2. Continued

\begin{tabular}{|c|c|}
\hline Questionnaire & $\mathrm{N}$ of respondents (\%) \\
\hline \multicolumn{2}{|l|}{$\mathrm{RBC}$ units issued in $2018^{\dagger}$} \\
\hline$<500$ & $1(1.6)$ \\
\hline 500-999 & $3(4.8)$ \\
\hline $1,000-4,999$ & $9(41.3)$ \\
\hline $5,000-9,999$ & $21(33.3)$ \\
\hline $10,000-49,999$ & $26(41.3)$ \\
\hline$\geq 50,000$ & $3(4.8)$ \\
\hline \multicolumn{2}{|l|}{$\mathrm{RBC}$ wastage in $2018^{\dagger}$} \\
\hline$<5$ & $6(9.5)$ \\
\hline $5-9$ & $10(15.9)$ \\
\hline $10-19$ & $11(17.5)$ \\
\hline $20-49$ & $16(25.4)$ \\
\hline $50-99$ & $15(23.8)$ \\
\hline 100-199 & $4(6.3)$ \\
\hline$\geq 200$ & $1(1.6)$ \\
\hline \multicolumn{2}{|l|}{ C:T ratio in $2018^{\dagger}$} \\
\hline 1.0 to $<1.1$ & $28(44.4)$ \\
\hline 1.1 to $<1.2$ & $16(25.4)$ \\
\hline 1.2 to $<1.3$ & $7(11.1)$ \\
\hline 1.3 to $<1.4$ & $3(4.8)$ \\
\hline$\geq 1.4$ & $9(14.3)$ \\
\hline \multicolumn{2}{|l|}{ Expected utility of TIs to reduce RBC wastage } \\
\hline High utility & $43(67.2)$ \\
\hline Low utility & $21(32.8)$ \\
\hline Reasons of expected low utility of Tls to reduce RBC wastage* & $21(32.8)$ \\
\hline Low RBC wastage due to violation of the 30 -minute rule & $17(81.0)$ \\
\hline Possibility to increase RBC wastage due to a too-fast color change of Tls & $11(52.4)$ \\
\hline Intra- or inter-observer variability in reading a color change of TIs & $7(33.3)$ \\
\hline
\end{tabular}

${ }^{*}$ Multiple choice; ${ }^{\top}$ The number of respondents was 63, excluding one from a newly opened hospital ( $<1$ year).

Abbreviations: RBC, red blood cell; RT, room temperature; TI, temperature-sensitive indicator; ST, surface temperature; GW, general ward; ICU, intensive care unit; OR, operating room; ED, emergency department; OC, outpatient clinic; C:T ratio, crossmatch to transfusion ratio.

(13.7\%, N=92) indicated experience of RBC unit discard due to violation of the 30-minute rule. Regarding the expected utility of TIs to reduce RBC wastage, $83.1 \%(\mathrm{~N}=559)$ and $16.9 \%$ $(\mathrm{N}=114)$ of nurses answered that Tls would have high and low utility, respectively. Reasons for the expected low utility of TIS were as follows: difficulty of reading a color change of TIs (76.3\%, $\mathrm{N}=87$ ), low RBC wastage due to violation of the 30-minute rule (62.3\%, N =71); possibility of delayed transfusion due to reading the color change of TIs $(62.3 \%, N=71)$, insufficient time to read the color change of Tls due to nursing tasks (46.5\%, N=53); and possibility to increase RBC wastage due to the fast color change of TIs $(1.8 \%, N=2)$.

\section{DISCUSSION}

This questionnaire survey of blood bank physicians and nurses focused on the practice for the blood cold chain of RBC units at a blood bank and bedside, and their awareness and expected utility of TIs. In particular, our survey focused on the awareness and compliance of the 30-minute rule, the practical situation of RBC transport, and possible utility of Tls to reduce RBC wastage. Most of the blood bank physicians answered that their hos- 
Park M, et al.

Survey on RBC Transport and Storage in Korea

Table 3. Summary of the survey to nurses $(N=673)$

\begin{tabular}{|c|c|}
\hline Questionnaire & $\mathrm{N}$ of respondents (\%) \\
\hline \multicolumn{2}{|l|}{ Presence of nursing practice guidelines for RBC transfusion } \\
\hline Yes & $616(91.5)$ \\
\hline № & $4(0.6)$ \\
\hline Unknown & $53(7.9)$ \\
\hline \multicolumn{2}{|l|}{ Contents of nursing practice guidelines for RBC transfusion* } \\
\hline Preparation for RBC transfusion & $614(99.7)$ \\
\hline Storage of RBC units until transfusion & $571(92.7)$ \\
\hline Storage temperature for $\mathrm{RBC}$ units & $558(90.6)$ \\
\hline Transport temperature for RBC units & $355(57.6)$ \\
\hline Nursing practice during intra-transfusion & $600(97.4)$ \\
\hline Standard and procedure for return and discard of RBC units & $615(99.8)$ \\
\hline Criteria for discard of RBC units after issue in nursing practice guidelines for RBC transfusion* & $615(99.8)$ \\
\hline Exposure to RT for over 30 minutes & $570(92.7)$ \\
\hline ST of $\mathrm{RBC}$ unit to reach $10^{\circ} \mathrm{C}$ & $251(40.8)$ \\
\hline Damaged RBC units & $555(90.2)$ \\
\hline Contaminated RBC units & $547(88.9)$ \\
\hline Withdrawal of RBC transfusion due to the change of patient's condition & $468(76.1)$ \\
\hline Transfusion-related adverse reactions & $528(85.9)$ \\
\hline \multicolumn{2}{|l|}{ Use of transport container to ward after issue } \\
\hline Yes & $666(99.0)$ \\
\hline No & $1(0.1)$ \\
\hline Unknown & $6(0.9)$ \\
\hline \multicolumn{2}{|l|}{ Types of transport container to ward after issue } \\
\hline Cooler only & $278(41.7)$ \\
\hline Cooler with refrigerant & $361(54.2)$ \\
\hline Cooler with refrigerant and TI & $8(1.2)$ \\
\hline Others (e.g., cool bag, plastic box, plastic bag) & $19(2.8)$ \\
\hline ST monitoring of RBC units at transport after issue & $8(1.2)$ \\
\hline Blood refrigerator equipped in ward or outpatient clinic & $200(29.7)$ \\
\hline GW & $83(41.5)$ \\
\hline ICU & $51(25.5)$ \\
\hline OR & $36(18.0)$ \\
\hline ED & $20(10.0)$ \\
\hline $\mathrm{OC}$ & $10(5.0)$ \\
\hline \multicolumn{2}{|l|}{ Storage time limit of RBC units in blood refrigerator at ward } \\
\hline$\leq 30 \mathrm{~min}$ & $6(3.0)$ \\
\hline$\leq 12 \mathrm{hr}$ & $9(4.5)$ \\
\hline$\leq 24 \mathrm{hr}$ & $170(85.0)$ \\
\hline$>24 \mathrm{hr}$ & $5(2.5)$ \\
\hline No standard & $2(1.0)$ \\
\hline Unknown & $8(4.0)$ \\
\hline
\end{tabular}


Table 3. Continued

\begin{tabular}{|c|c|}
\hline Questionnaire & $\mathrm{N}$ of respondents (\%) \\
\hline \multicolumn{2}{|l|}{ Monitoring of temperature of blood refrigerator at ward } \\
\hline Electronic monitoring only & $40(20.0)$ \\
\hline Electronic monitoring with regular check by clinical nurses & $148(74.0)$ \\
\hline Unknown & $12(6.0)$ \\
\hline Knowledge about the 30 -minute rule & $669(99.4)$ \\
\hline Compliance of the 30 -minute rule & $666(99.0)$ \\
\hline Experience of discard of RBC units due to violation of the 30 -minute rule & $92(13.7)$ \\
\hline \multicolumn{2}{|l|}{ Reasons of discard of RBC units due to violation of the 30-minute rule* } \\
\hline Withdrawal of transfusion due to change of patient's condition & 77 (11.4) \\
\hline Delayed transfusion due to other nursing tasks & $12(1.8)$ \\
\hline Delayed transport of RBC units & $2(0.3)$ \\
\hline Exposure to RT over 30 minutes after issue & $1(0.2)$ \\
\hline Failed blood refrigerator in ward & $1(0.2)$ \\
\hline Patient's absence & $1(0.2)$ \\
\hline \multicolumn{2}{|l|}{ Expected utility of TIs to reduce RBC wastage } \\
\hline High utility & $559(83.1)$ \\
\hline Low utility & $114(16.9)$ \\
\hline Reasons of expected low utility of Tls to reduce RBC wastage* & $114(16.9)$ \\
\hline Difficulty of reading a color change of Tls & $87(76.3)$ \\
\hline Low RBC wastage due to violation of the 30 -minute rule & $71(62.3)$ \\
\hline Possibility of delayed transfusion due to reading a color change of Tls & $71(62.3)$ \\
\hline Insufficient time to read a color change of Tls due to nursing tasks & $53(46.5)$ \\
\hline Possibility to increase RBC wastage due to a too fast color change of Tls & $2(1.8)$ \\
\hline
\end{tabular}

*Multiple choice.

Abbreviations: RBC, red blood cells; OC, outpatient clinic; RT, room temperature; ST, surface temperature; TI, temperature-sensitive indicator; GW, general ward; ICU, intensive care unit; OR, operating room; ED, emergency department.

pitals have RBC transfusion guidelines that include standards for RBC unit discard after issue. Although most of the guidelines include details about RBC unit transport to the ward after issue, this is generally not accompanied by detailed protocols defining transport conditions, including the transport container and/or temperature monitoring. Most of the nurses also answered that their hospitals have nursing practice guidelines for RBC transfusion that include the standard for RBC unit discard. However, only slightly more than a half (57.6\%) answered that the content of transport temperature for RBC unit was included in the guidelines.

The majority of the RBC transfusion guidelines in the blood bank and nursing practice guidelines for RBC transfusion included the 30-minute rule as the standard for discard of RBC units after issue. However, the content of ST monitoring of RBC units during transport was rarely included in either guideline type. Approximately half of the blood bank physicians answered that they do not use a refrigerant during transport of RBC units to maintain transport temperature. Although most nurses were aware of and complied with the 30-minute rule, one veteran nurse with clinical experience of more than 10 years and three nurses with clinical experience $<5$ years were not aware of the 30-minute rule. Among them, only two nurses answered that they have nursing practice guidelines for RBC transfusion including the 30-minute rule. Taken together, it seems that both blood bank physicians and nurses are aware of the importance of the blood cold chain, are familiar with the 30-minute rule and $10^{\circ} \mathrm{C}$ rule, and follow the 30 -minute rule. In actual practice, little attention has been paid to RBC transport compared with RBC storage, and no detailed protocols and/or guidance have been prepared for the same. National guidelines and/or guidelines from professional societies are needed for the safe transport of 


\section{RBC units.}

Regarding the wastage rate of $\mathrm{RBC}$ units, in the three of the participating hospitals, the RBC wastage rate ranged from $0.02 \%$ to $0.26 \%$. In one of the three hospitals, $2.4 \%(\mathrm{~N}=2)$ of the RBC wastage was due to violation of the 30-minute rule (83 RBC units discarded in 2018). Among nurses with experience of RBC unit discard due to violation of the 30-minute rule, $0.5 \%(\mathrm{~N}=3)$ answered that an RBC unit was discarded due to delayed transport or exposure to room temperature (RT) for over 30 minutes. Kim, et al. [23] reported that $0.6 \%(N=1)$ of blood units were discarded due violation of the 30-minute rule among 162 discarded blood units. Only 5.5\% ( $\mathrm{N}=3$ ) of blood bank physicians answered that the GW was equipped with a blood refrigerator; however, $41.5 \%(\mathrm{~N}=83)$ of nurses answered that their GW was equipped with a blood refrigerator. Since the survey to nurses was conducted anonymously, it is possible that this response referred to the same specific GWs.

In nursing practice, the storage time limit of RBC units in blood refrigerators at the ward varied, with the highest response of 24 hours. One nurse replied that the storage time limit of RBC units was set at 24 hours in the blood refrigerator at ward, but that the majority of RBC transfusions were performed within 30 minutes after issue. The WHO stated that it takes at least 30 minutes for a blood bank refrigerator with a full load of blood units set to $4^{\circ} \mathrm{C}$ to reach up to $6^{\circ} \mathrm{C}$; however, no statement is provided on the time limit for storage in a blood refrigerator at the ward after issue regarding the 30-minute rule [8]. A time limit up to 60 minutes is acceptable for RBC units outside of controlled temperature [8, 11, 24]. RBC units exposed to uncontrolled temperature conditions for 60 minutes should be cooled down below $6^{\circ} \mathrm{C}$ for over 6 hours prior to reissue [2]. No significant change in $\mathrm{RBC}$ quality was found at temperatures higher than $10^{\circ} \mathrm{C}$ or with storage times longer than 30 minutes $[25,26]$. Thus, the 30-minute rule has been amended to the 60-minute rule in the United Kingdom and Canada [24, 27, 28], resulting in significantly reduced RBC wastage [28]. Although we did not survey the actual wastage rate of RBC units and the overall rate of RBC wastage due to violation of the 30-minute rule nationwide, it is expected that the RBC shortage would increase. Blood donations could decrease under certain circumstances, including outbreaks of infectious diseases, such as COVID-19, and a decrease of eligible blood donors due to demographic changes given the declining birth rate and aging society [29, 30]; the increase in elderly people may also be associated with an increased demand of RBC usage [31]. Taken together, the customary 30minute rule should be reconsidered in the face of contemporary society; extending or changing this time rule should also be considered in other countries.

The majority of blood bank physicians (67.2\%) and nurses (83.1\%) answered that TIs would have high utility to reduce RBC wastage; however, the distribution of reasons for the expected low utility of TIs to reduce RBC wastage varied between blood bank physicians and nurses. Most blood bank physicians and nurses who indicated that TIs would not be helpful answered like that because of the current low rate of RBC discard due to violation of the 30-minute rule. Moreover, more than a half of the blood bank physicians who selected the expected low utility of TIs answered that TIs could potentially increase RBC wastage due to the too-fast color change. Most of the nurses $(76.3 \%$, $\mathrm{N}=87$ ) who selected the expected low utility of TIs answered that the interpretation of a color change of TIs would be difficult.

The time for a color change indicating $10^{\circ} \mathrm{C}$ varies across different TIs; in one study, more than $90 \%$ of TIs already showed a color change indicating $10^{\circ} \mathrm{C}$ within 30 minutes under RT [5, 15-17]. Various factors affect the color change of TIs [5]. Reportedly, $87.4 \%$ of RBC units were discarded due to violation of the 30-minute rule after issue or color change of TIs among total discarded RBC units [32]. Intra- or inter-observer variability is also a concern in interpretation of the color change [5, 15]; in a recent study, time-temperature indicators (TTIs) showed better performance than TIs [17]. Although TIs could serve as a supplementary tool to reduce RBC wastage, several limitations, including performance, should first be overcome [5, 17, 32]. Although not included in the survey, the cost concerns and costeffectiveness of TIs might have also resulted in selecting the "low utility" option.

This study has several limitations. First, the survey subjects were limited to blood bank physicians and nurses working at secondary- or tertiary-care hospitals in Korea, which were concentrated in Seoul, Incheon, and Gyeonggi-do. Although transfusion is conducted in approximately 2,500 medical institutions, our survey focused on blood bank physicians and nurses in hospitals where RBC transfusions are expected to be performed frequently [33]. Since the survey to nurses was conducted anonymously, we could not further analyze the results according to hospitals and wards; accordingly, there is a possibility that some survey results may have been derived from a few specific hospitals, leading to bias. Second, this survey did not include questions about the status of RBC transfusion within 30 minutes after issue, the wastage rate of an RBC unit due to delayed transfusion, regular education on RBC transfusion guidelines for nurses, and nursing practice at the ward, including the method of stor- 
age and discard of an RBC unit after issue. Further surveys with a larger study population and more detailed questions are needed to more accurately reflect the status of blood cold chain nationwide.

In conclusion, we conducted a survey of both blood bank physicians and nurses on RBC transport and storage in real hospital settings. This study provides fundamental data on the current practice for blood cold chain, and understanding about RBC wastage and the expected utility of TIs. Based on our survey results, to maintain the blood cold chain and guarantee safe transfusion practice, it is necessary to prepare detailed consensus guidelines and/or protocols on RBC transport and storage steps. It should also be mandatory to educate and guide medical personnel in these guidelines adequately.

\section{ACKNOWLEDGEMENTS}

None.

\section{AUTHOR CONTRIBUTIONS}

Park M conducted the study, analyzed the data, and wrote the draft; Hur M conceived the study, analyzed the data, and finalized the draft; Kim H, Oh KM, Kim H, and Song YH discussed the data and reviewed the manuscript; Ko DH and Chung YS participated in the data analysis. All authors critically reviewed the manuscript and approved the final version.

\section{CONFLICTS OF INTEREST}

No potential conflicts of interest relevant to this article are reported.

\section{RESEARCH FUNDING}

This study was supported by Division of Blood Safety Surveillance, Korea Centers for Disease Control and Prevention (No. 2019E830400).

\section{ORCID}

Mikyoung Park

Mina Hur

Hahah Kim

Kyungmi Oh

Hyunmi Kim
Young Hye Song

Dae-Hyun Ko

Yousun Chung

\section{REFERENCES}

1. Lelubre $\mathrm{C}$ and Vincent JL. Red blood cell transfusion in the critically il patient. Ann Intensive Care 2011;1:43.

2. de Bruin S, Scheeren TWL, Bakker J, van Bruggen R, Vlaar APJ; Cardiovascular Dynamics Section and Transfusion Guideline Task Force of the ESICM. Transfusion practice in the non-bleeding critically ill: an international online survey-the TRACE survey. Crit Care 2019;23:309.

3. Alquist CR and Harm S. Transfusion service-related activities: pretransfusion testing and storage, monitoring, processing, distribution, and inventory management of blood Components. In: Cohn CS, ed. Technical manual. 20th ed. Bethesda: American Association of Blood Banks, 2020: 503-35.

4. Korea Centers for Disease Control \& Prevention. Transfusion guideline. 4th ed. http://www.transfusion.or.kr/KOR/images/file/4_file01.pdf (Last accessed: 16 March 2021).

5. Park M, Hur M, Yi A, Kim H, Lee HK, Jeon EY, et al. Utility of temperature-sensitive indicators for temperature monitoring of red-blood-cell units. Vox Sang 2019;114:487-94.

6. Pick $P$ and Fabijanic J. Temperature changes in donor blood under different storage conditions. Transfusion 1971;11:213-5.

7. World Health Organization. Clinical transfusion practice. https://www. who.int/bloodsafety/transfusion_services/ClinicalTransfusionPracticeGuidelinesforMedicallnternsBangladesh.pdf (Last accessed: 16 March 2021).

8. World Health Organization. The blood cold chain. https://www.who.int/ bloodsafety/testing_processing/components/en/BloodColdChain.pdf?ua=1 (Last accessed: 16 March 2021).

9. Yazer MH, Abraham S, Beckman N, Folléa G. International Society for Blood Transfusion international survey on blood product wastage in hospitals. ISBT Sci Ser 2016;11:24-31.

10. Hamill TR. The 30-minute rule for reissuing blood: are we needlessly discarding units? Transfusion 1990;30:58-62.

11. Dumani D, Goldfinger D, Ziman A. Is the 30-minute rule still applicable in the 21st century? Transfusion 2013;53:1150-2.

12. Kurup R, Anderson A, Boston C, Burns L, George M, Frank M. A study on blood product usage and wastage at the public hospital, Guyana. BMC Res Notes 2016;9:307.

13. NHS blood stocks management scheme. NHS Blood and Transplant hospital report 2017-18. https://nhsbtdbe.blob.core.windows.net/umbraco-assets-corp/15951/nhsbt-annual-report-2017-18.pdf (Last accessed: 16 March 2021).

14. Johnson V, Langeberg A, Taye-Makuria A, Sandler SG. Temperaturesensitive labels for containers of RBCs. Am J Clin Pathol 2006;126:40610 .

15. Sigle JP, Holbro A, Lehmann T, Infanti L, Gerull S, Stern M, et al. Temperature-sensitive indicators for monitoring RBC concentrates out of controlled temperature storage. Am J Clin Pathol 2015;144:145-50.

16. Tiwari AK, Sharma P, Pandey PK, Rawat GS, Dixit S, Raina V, et al. A cost effective model for appropriate administration of red cell units and salvaging un-transfused red cell units by using temperature sensitive indicators for blood component transportation in a hospital setting. Asian J Transfus Sci 2015;9:36-40.

17. Park M, Hur M, Kim H, Oh K, Ko DH, Chung Y. Time-temperature indi- 
cators versus temperature indicators for transfusion practice: application in the real hospital setting. Vox Sang 2021 July 28. doi: 10.1111/ vox.13182. Online ahead of print.

18. Bots M, de Grouw EP, van Rooyen-Schreurs IH, van den Akker GJ, Sturk A, Klinkspoor JH, et al. Strategies to reduce wastage of red blood cell units. Vox Sang 2016;110:143-9.

19. Gallagher T, Darby S, Vodanovich M, Campbell L, Tovey J. Patient blood management nurse vs transfusion nurse: is it time to merge? Br J Nurs 2015;24:492-5.

20. Nakamura Y, Furuta Y, Tokida M, Ichikawa K, Shirahata M, Uzawa K, et al. A survey of nurses to assess transfusion practice at the bedside using an electronic identification system: experience at a university hospital. Transfus Med 2021;31:5-10.

21. Ddungu H, Krantz EM, Phipps W, Naluzze S, Orem J, Kiwanuka N, et al. Survey to assess knowledge and reported practices regarding blood transfusion among cancer physicians in Uganda. J Glob Oncol 2018; 4:1-12.

22. Islami Vaghar M. The impact of an educational program on blood and blood products transfusion on nurses' level of knowledge and performance. J Med Life 2018;11:238-42.

23. Kim BS, Seo YI, Chai GR, Shin JW, Choi TY. Analysis of discarded blood components at a university hospital in Korea. Korean J Blood Transfus 2011;22:120-6.

24. SPECIFICATION SPN223/10 NHSBT portfolio of blood components and guidance for their clinical use. https://nhsbtdbe.blob.core.windows. net/umbraco-assets-corp/16494/spn223v10.pdf (Last accessed: 16 March 2021).

25. Thomas S, Hancock V, Cardigan R. The 30 minute rule for red blood cells: in vitro quality assessment after repeated exposure to $30^{\circ} \mathrm{C}$. Transfusion 2013;53:1169-77.

26. Ramirez-Arcos S, Mastronardi C, Perkins H, Kou Y, Turner T, Mastronardi E, et al. Evaluating the 4-hour and 30-minute rules: effects of room temperature exposure on red blood cell quality and bacterial growth. Transfusion 2013;53:851-9.

27. Ramirez-Arcos S, Kou Y, Ducas É, Thibault L. Changing the 30-min rule in Canada: the effect of room temperature on bacterial growth in red blood cells. Transfus Med Hemother 2016;43:396-9.

28. Aplin K, Pitt T, Allen J, Roy A, Tidey K, Ball J, et al. Extending the 30-minute rule for red cell units-investigation of the bacterial risk of 60-minute exposures to ambient temperature. Vox Sang 2019;114:189-97.

29. Stanworth SJ, New HV, Apelseth TO, Brunskill S, Cardigan R, Doree C, et al. Effects of the COVID-19 pandemic on supply and use of blood for transfusion. Lancet Haematol 2020; 7:e756-64.

30. Müller-Steinhardt M, Müller-Kuller T, Weiss C, Menzel D, Wiesneth M, Seifried E, et al. Safety and frequency of whole blood donations from elderly donors. Vox Sang 2012;102:134-9.

31. Ali A, Auvinen MK, Rautonen J. The aging population poses a global challenge for blood services. Transfusion 2010;50:584-8.

32. Heitmiller ES, Hill RB, Marshall CE, Parsons BJ, Berkow LC, Barrasso $\mathrm{CA}$, et al. Blood wastage reduction using Lean Sigma methodology. Transfusion 2010;50:1887-96.

33. Chun S, Choi JS, Jung YZ, Shin JW, Jeong KE, Oh JA, et al. Survey on the preparation status of medical institutions regarding the full revision of the Korean Blood Inventory Monitoring System. Korean J Blood Transfus 2020;31:211-21. 